\title{
4 Supporting students' summary writing skills in English medium instruction in the university context
}

\author{
Yangyu Xiao and Hintat Cheung
}

\section{Introduction}

English as a medium of instruction (EMI) has become increasingly popular in the Asia-Pacific higher education sector (Walkinshaw et al., 2017). EMI education has led to the internalization of higher education, improved reputation of universities, improved language proficiency among teachers and students, and greater mobility for graduates; however, the wide use of EMI education has also created challenges in teaching and learning subject knowledge in a foreign or second language, and poses a threat to the status of local languages in the academic context (Walkinshaw et al., 2017). One major concern in EMI education is whether students have sufficient English proficiency to meet the demands of their academic study, and how such discipline-specific language needs (such as the ability to write in a disciplinespecific context) can be catered to. Whereas scholarly articles have revealed that students experience challenges in studying subject matter in a second or foreign language, how to help students develop their English language proficiency in their own disciplinary study is still a topic worth further investigation (Yildiz et al., 2017).

The study being discussed investigates students' discipline-specific language needs at one Hong Kong university that uses EMI and how such needs can be addressed through their experiences in using an online disciplinespecific summary writing platform. To enhance students' discipline-specific summary writing skills, an online writing platform was created, and summary writing workshops were provided to a group of university students in Hong Kong. Data were collected through semi-structured interviews with nine students after they attended the summary writing workshops and experienced the online learning platform. The current study documents students' perceptions of their discipline-specific writing experience and discusses pedagogical implications of meeting students' discipline-specific language learning needs. 


\section{Supporting discipline-specific summary writing in the EMI context}

The literature review was framed by three inter-related themes which highlight the necessity to support discipline-specific summary writing in the EMI context: 1) the benefits and challenges of EMI education, 2) discipline-specific language learning needs in the EMI context, and 3) summary writing as an academic writing skill.

\section{English as a medium of instruction}

There is an increasing tendency to use EMI in higher education in various geographical areas around the world (Dearden, 2014). The use of EMI dates back to the 1950s in Europe. The growth of the European Economic Community led to a need to provide multilingual and multicultural education (Barnard, 2014). EMI has become popular in Asian universities recently. Many places in Asia, like Hong Kong, Singapore, the Philippines, and Malaysia, are using English as a medium of instruction in the university context. A number of universities in Britain, American, and Australia are collaborating with Asian universities to provide EMI programs through co-teaching; some have even gone further to establish their own overseas campus (Barnard, 2014).

One major motivation of using EMI in universities is the trend toward internationalization. EMI is considered to bring several benefits, such as providing students with better career opportunities and chances for academic advancement in an international context, attracting international students and academics, enhancing universities' international connectedness and competitiveness, and satisfying the needs of intellectual exchange (see Byun et al., 2011; Macaro et al., 2017; Werther et al., 2014).

Whereas EMI has had a positive impact as expected, it has also met challenges. One commonly addressed challenge is the English language competence of university lecturers and students (Barnard, 2014). In a case study of EMI in the Chinese tertiary context, Hu and Lei (2014) revealed that the faculty members' inadequate English language proficiency was a main constraint for teaching effectively, as they could not deliver and explain instructional content competently. Similarly, students' insufficient English language competence made it difficult for them to comprehend the instructional content and express what they have learned in English (Hu \& Lei, 2014). In addition, it was observed that when lecturers taught content courses, there was little room for facilitating the development of students' competence in their discipline-specific language. In a study of medical teachers' and students' perceptions of EMI programs in China, Jiang et al. (2019) observed that the classroom language of content courses were featured technical language and subject specific sentence structures, with little attempt made at unpacking the discipline-specific language. The above literature reveals a dilemma arising from the university's desire to promote EMI education and the inadequacy of discipline-specific English language competence. Thus, there seems to be 
a gap between what the university desires to do and what the lecturers and students encounter in the implementation.

\section{Discipline-specific language learning needs}

English for academic purposes courses have been offered in many universities to enhance students' language proficiency (Barnard, 2014); however, students still feel frustrated about their language abilities in coping with their disciplinary courses. In a study of Korean medical students' perceptions of their EMI learning experience, students hoped that more support could be provided by the university to increase their learning efficiency. Students expected that they could obtain more language support through taking discipline-specific English language courses, such as medical English courses, English remedial courses, or sessions where teachers could explain medical terms and jargon in English (Joe \& Lee, 2013). This study indicates that merely providing academic English courses is insufficient for students who plan to study in an EMI context.

In Hong Kong, Evans and Green (2007) conducted a large-scale survey focusing on university students' linguistic difficulties in an EMI university. The findings show that students had problems with academic vocabulary, academic writing, and speaking. Regarding writing, students reported that they had little confidence regarding all aspects of academic writing, such as summarizing, paraphrasing, and synthesizing information. Such findings support the needs to study discipline-specific language learning requirements to help students to study more effectively in an EMI context.

The current chapter focuses on discipline-specific language learning from the angle of academic writing, inasmuch as academic writing is a key skill that students need in an EMI context. Essentially, effective academic writing in students' own subjects requires a variety of subject-specific literacies. Through these literacies, members of disciplines communicate with their peers, and students with their professors in a more professional way (Hyland, 2002). In a study exploring the academic writing needs of students of the University of British Columbia for whom English is not their first language, students considered that writing was the most important skill (followed by reading, speaking, and listening). In terms of writing needs, students expected academic writing courses to help them in the following areas: gaining a good command of standard written English, using examples to support a position, organizing ideas effectively, writing on the topic with precision, and using vocabulary appropriate to the topic (Huang, 2010).

\section{Summary writing as an academic English skill}

The current study focuses specifically on summary writing as a writing skill that students frequently use. Writing a summary in English is essential for academic learning in EMI programs, but is an especially difficult 
skill when students need to complete their theses or project reports in their second or foreign language. Summary writing requires the ability to identify main ideas from source information, to synthesize, and to convey this information succinctly and coherently in writing (Landauer \& Psotka, 2000). Conventionally, summary writing has only been employed as language learning practice. However, extensive research in higher education has shown that summary writing can also be used as an efficient tool to serve knowledge construction in different disciplines (Klein et al., 2014) and to enable students to engage in deeper learning (Wade-Stein \& Kintsch, 2004). Research has also shown that summary writing as a tool of learning produces better results if combined with revision practices following corrective feedback (Bitchener, 2008). In considering the popularity of EMI education and the importance of developing discipline-specific language needs in EMI education, the current study intends to answer the following research questions:

1 What are students' perceptions of EMI education and their disciplinespecific English language learning needs?

2 To what extent can disciplinary summary writing workshops address their discipline-specific language needs?

3 What are the selected university students' perceptions of the online summary writing platform?

\section{Research methods}

The current study was a small-scale project intended to foster students' discipline-specific summary writing skills in an EMI context.

\section{The context}

The current study was conducted in a university in Hong Kong where English was used as the medium of instruction for most of the subjects, except for some general education courses and Chinese courses. English was used in classroom teaching, assignments, and assessments. Most of the students spoke Chinese (mainly Cantonese and the rest Mandarin) as their mother tongue; many went to schools where Chinese was used as the medium of instruction before they came to the university.

Supporting students' discipline-specific language learning needs has become a major task for the university. Among all language skills, writing summaries in English is an essential skill for learning given that undergraduate students need to complete a research project in their final year and postgraduate students need to write up research papers frequently. However, students usually struggle with this critical academic skill. One possible reason leading to this situation is that summary writing is a higher-order skill that 
requires discipline-based practice guided by structured writing tasks and tailor-made feedback; it requires a close integration of language teaching and disciplinary knowledge. Thus, the current study was conducted in such a context, with the purpose of supporting students' summary writing skills within their specific disciplines.

\section{The discipline-specific summary writing platform}

To support students' discipline-related language learning experience, an online discipline-specific summary writing platform was constructed. The online writing platform gave students the opportunities to practice their summary writing skills by themselves at their own pace.

The construction of the summary writing platform proceeded in five stages: 1) the research team collaborated with content teachers from different departments to select key literatures that students needed to read for their own disciplinary courses; 2) PhD or master's students from the related disciplines were invited to develop expert summaries which were used as the exemplar summaries on the platform; 3 ) the expert summaries were edited and polished by language experts after completion; 4) an IT technician developed an algorithm which could compare students' summaries and expert summaries (on the same topic), so as to generate a content score based on the quality of the summary, and 5) the PiGai platform (a tool similar to Grammarly) was integrated into the summary writing platform to generate feedback on the language.

When students submitted their summaries on the writing platform, they received a score indicating their performance on the content, as well as feedback on language. One sample summary was shown on the screen for students' reference. In this way, the online summary writing platform offered students both feedback on language and a score indicating their performance on content. In addition, students were asked to self-reflect on their own summary by answering a series of questions on how well they had completed the task (see Appendix 4A) and write their reflections. The self-reflection exercise encouraged students to reflect on whether their summaries achieved the expected standard. To sum up, the key purpose for adopting the disciplinespecific summary writing platform was to provide discipline-specific language support to students, with the purpose of fostering the language proficiency needed in an EMI context.

When the platform was ready, the research team organized three three-hour discipline-specific summary writing workshops where students were trained in summary writing skills and then asked to write their summaries on the online summary writing platform. Each student was required to attend only one workshop, and 30 students in total attended the workshops. While the study is small scale, it is sufficient to act as an exploratory study of students' perceptions of such a learning experience. 


\section{Data collection and analysis}

To obtain students' perceptions of the summary writing platform and their learning experience of discipline-specific summary writing, semi-structured interviews were conducted with nine students majoring in mathematics, composed of seven undergraduate students and two master's students. All the participants have attended the summary writing workshops and used the online learning platform. Each interview lasted for around one hour. All interviews were conducted in the language that both the students and the interviewer were most familiar with (Cantonese or Mandarin). All interviews were transcribed and translated into English after coding.

To provide answers to the research questions mentioned earlier, the interview questions focused on students' perceptions toward three major issues: 1) EMI education in the university context, 2) discipline-specific summary writing workshops, and 3) experience of online summary writing. The interview questions were developed to obtain students' perceptions of their discipline-specific language learning needs, and the extent to which the discipline-specific summary writing training met their needs.

Data were analyzed through NVivo 11. The theoretical framework as established in the literature reviewed guided the data analysis with all data coded under three main themes: benefits and challenges of EMI, disciplinespecific language learning needs, and perceptions of discipline-specific language training. The subcodes emerged from data in a grounded way. After the initial round of coding, the research team discussed the major themes and codes emerged.

\section{Findings}

The findings section focuses on four main themes: 1) students' perceptions of EMI education, 2) students' perceptions of discipline-specific summary writing workshops, 3) students' discipline-specific language learning needs, and 4) students' perceptions of the online summary writing platform.

\section{Students' perceptions of EMI education: Benefits}

Student participants addressed multiple benefits of EMI education. One major benefit agreed on by students was that EMI education offered them chances of future development, as shown in the responses below:

EMI education is good, in particular if you want to pursue further academic studies in the future.

(Sunny)

EMI is necessary if you want to go abroad for further studies. 
Both Sunny and Sonia's responses show that EMI education is an important pathway if students would like to pursue further studies in a different country. Such an opinion can be further supported by the viewpoint that EMI plays a key role in internationalization.

Susan, a master's student in Mathematics Education, articulated that EMI education provided her chances to study education pedagogy in different countries:

Through learning math pedagogy through English, I had a better and a deeper understanding of pedagogy in Western countries... More importantly, if I want to do a $\mathrm{PhD}$, I will need to read a lot of resources in English.

(Susan)

Susan's response shows that EMI education opens a door for students to get access to different resources in English. Sally, another master's student, mentioned explicitly that with sufficient English language proficiency in her own discipline, she had more chances to survive in an internationalized era. The above-mentioned students' responses show that EMI education provides them more choices for future study and career.

Sarah, a student majoring in primary mathematics, felt that EMI education enhanced her professionalism. English is now an official language in Hong Kong, and many professionals - such as doctors, lawyers, and academic professors - have an excellent command of English. Sarah felt that she had a sense of professionalism arising from her good language proficiency in her discipline. Susie, a student majoring in secondary mathematics, pointed out that the sense of being professional was also related to the fact that under EMI education she has developed a better understanding of mathematical terminology and usage in English; thus, she would be able to use these better in an international context.

EMI education also helped students improve their English language proficiency. Sandra, a final year mathematics student, admitted that she had difficulties in learning math through English at the beginning; however, after several years of study, she had made improvement in discipline-specific language proficiency. She now felt more comfortable attending lectures in English and completing assignments in English.

In summary, EMI education seems to benefit students by helping them improve their discipline-specific language proficiency, which provides them with more chances to study and work in an international context.

\section{Students' perceptions of EMI education: Challenges}

Despite the many benefits of EMI education, students in the study felt that current EMI education was constrained by the English language proficiency of both lecturers and students. 
Student participants pointed out the teachers' oral proficiency constrained their understanding of the subject matter, as stated in the response below:

Most mathematics teachers had a strong accent, and it was hard for me to understand the content. I would prefer them to speak Cantonese.

(Sunny)

Sunny's response shows that in the EMI context, the subject teacher's language proficiency reduced the effectiveness of classroom instruction thus, affecting students' comprehension of the content. This issue was more clearly elaborated by another student:

My lecturer has excellent knowledge of the discipline, and his research is also in this area. He can speak fluently; however, I still felt that he could not express his meaning clearly to us. Many of my classmates found it too difficult to complete his course.

(Susie)

Susie's response further supports that her lecturer's insufficient oral English skills hindered students' comprehension of subject-matter knowledge. Sarah had a similar opinion. To compensate for her difficulty in understanding the lectures, she had to study lecture notes after class.

Some students also admitted that they themselves did not have adequate English language proficiency to cope with EMI education. Sarah, a Year 2 student majoring in primary mathematics, responded that as Cantonese was used as the medium of instruction in both her primary and secondary schools, she experienced quite a lot of difficulty at the beginning, as she knew nothing about mathematical terms in English. Stella, a Year 2 student majoring in secondary mathematics, expressed her difficulty in learning mathematics through English despite experience of EMI education in her secondary school, as shown in the response below:

Learning mathematics through English is difficult for many students who are not good at English. My secondary mathematics were taught through English, but I still had difficulties. There were still a lot of new terms that I could not understand. I had no idea what teachers were talking about or how to use these mathematical symbols... but things seemed to have gotten better since Year 2.

(Stella)

Stella's response shows that insufficient discipline-specific language proficiency made it difficult for her to understand the lectures and put what she had learned in class into use. The negative impact of insufficient English language proficiency on the study of content knowledge was also evident in Sonia's response: 
I am not good at English and I have a limited vocabulary. I found it hard to understand teachers' English and thus, I could not learn the subject matter well.

(Sonia)

Sonia's response shows that she attributed ineffective learning of the subject matter to her insufficient English language proficiency and the use of English as a medium of instruction. It is possible that students might learn the subject matter better in a language they are more familiar with. Such responses indicate that to support students learning in EMI universities, attention needs to be paid to the discipline-specific English language learning.

\section{Experience of discipline-specific summary writing workshops}

One of the important purposes of the current project is to support disciplinespecific language learning. In the interviews, students were asked to comment on their perceptions of the effectiveness of the discipline-specific summary training workshops.

Students commented that the benefits of discipline-specific summary writing workshops were threefold. First, students were able to study summary writing skills in a discipline that they were familiar with, as shown in Sonia's response below:

I am grateful that we had such a workshop; our reading was related to primary mathematics. We have never had such summary workshops related to our major like this before. It made it easier for me to understand math literature.

(Sonia)

Sonia's response shows that when studying summary writing skills in her own discipline, it was easier for her to understand the related content. It seems that a discipline-specific language learning experience facilitated the development of language skills. Stella related such learning experience more closely to the disciplinary study:

The mathematics articles are more interesting. We will have to read mathematics articles when we conduct our research project in Year 4. It will be great if we can have similar workshops when we do these research projects.

(Stella)

As a Year 4 student, Stella seemed to relate the disciplinary language training more closely to the research project she will work on in her final year. As she explained, she needs to write a literature review when doing the project and 
thus, summary writing will be an important skill. However, currently the university does not provide sufficient discipline-specific language courses, which indicates that further improvement in the course design is needed.

Second, the discipline-specific summary workshops helped students strengthen their summary writing skills. Sally, a postgraduate student, responded that she could apply the skills she learned in the workshop to study in her own discipline:

After the summary writing workshop, I had an assignment in my own major course which required me to write a summary and then conduct a peer review. I used the skills we discussed in the workshop in my own writing. My peer commented that my summary was professional.

(Sally)

Sally's response indicates that she can apply the skills she obtained in the summary writing workshop to a different writing task in courses in her own discipline. This seems to support the idea that language skills obtained from a discipline-specific language learning experience can support learning in discipline-specific courses.

Sarah responded with a more specific comment on what she had learned from the workshop, as noted below:

The workshop helped me to write a summary in an organized way. Before attending this workshop, I wrote a summary according to the sequence that the information occurred in. Now I know I need to start with a statement of purpose, then discuss the key issues, and finally end it with a conclusion. In my view, this kind of summary is more complete.

(Sarah)

Sarah's response shows that the summary writing workshop taught her how to write an organized summary and she was able to clearly articulate what she had learned. Sarah believed that it was likely that she would have a better idea of how to write a project report in her final year as the workshop informed her of the key elements of a good summary. It seems that the discipline-specific summary writing workshops raised students' awareness of how to write a good summary, and the skills they obtained in the workshops are likely to be transferable.

The skills students obtained from summary writing workshops also went beyond summary writing itself. Susan exemplified that her lecturer in mathematics gave her a few theoretical articles on mathematics pedagogy recently and asked her to identify the strategies that she could use in her own teaching. She applied the skill of "identifying the main ideas of a passage" which she has learned in the summary workshops and found that she was able to grasp the key points much faster. Similarly, Sandra, a Year 5 student who was working on her final year project report at the time of the workshop, addressed how 
she applied the skills the teachers covered in the summary writing workshop to the writing-up of her literature review.

I am now working on the literature search for my final year project report. I know I need to pay attention to the first paragraph, the topic sentences and the abstract, and to search for any further information I need. I know how to summarize a source once I have read it.

(Sandra)

To sum up, the discipline-specific summary writing workshops seemed to play a supportive role in student learning by providing students with the opportunity to study language skills within the context of a discipline which they were familiar with. The discipline-specific summary writing workshops seemed to raise students' awareness of elements which they need to pay attention to when writing a summary, such as structure, organizational strategies, strategies for extracting useful information from the text, and chances for further practices of summarizing skills.

\section{Summary writing and discipline-specific language learning needs}

Despite the perceived effectiveness of summary writing training, there appeared to be a gap between discipline-specific language learning needs and the summary writing workshops the research team offered. Students pointed out that the summary writing workshops did not fully meet the learning needs of mathematics students, as shown in the responses below:

We had few chances to write a summary in our own major courses. Most of time, we took examinations.

(Susie)

As a Year 2 student, I need to write lesson plans and articles on teaching pedagogy. We seldom need to write a summary.

(Sarah)

Susie considered that mathematics students have little need to write essays, compared with students studying English language education. Sarah's response indicates that the writing tasks required in her own major did not include summary writing tasks. It is understandable that undergraduate mathematics students may have their own discipline-specific language learning needs. Thus, to support disciplinary learning in the EMI context, teaching of academic English skills must address students' language learning needs as determined by their own disciplines.

Compared with undergraduate students who probably had fewer chances to write, postgraduates tended to believe that the summary writing workshops were beneficial. 
As a postgraduate student, I found the workshops very helpful. I wrote an abstract and a summary last month and again two days ago.

(Sally)

I need to write several reports this semester. It is good for us to learn the skills required to write a good essay. We may use the ability when we apply for doctoral study later.

(Susan)

Sally and Susan's responses show that they perceived the summary writing training to be more relevant to them, probably because postgraduate students need to engage more in high-order academic writing in their discipline, so as to showcase what they have learned. The perceived relevance to students' current and future study affects their perceptions of the effectiveness of the workshops.

When asked what language support the university has offered and to what extent they considered that support to be effective, students responded that the university only offered generic English for Academic Purposes courses.

We have academic writing in Year 1. But this is not helpful. It is just one general English course and there was nothing about our discipline.

(Stella)

We have a course called "Sets and Logic." In that course, the teacher helped us revise all the symbols in English, and we studied logic in English again. It helped us to get accustomed to the English in university.

(Sammy)

Students' responses above indicate that currently in their university the language teachers and discipline teachers work separately to offer either general English courses or disciplinary courses. However, insufficient efforts have been put into the integration of the two, to address students' disciplinespecific language learning needs. Students' responses indicate that it would be helpful for universities to offer discipline-specific language courses. In addition to writing summaries, students also identified a number of areas of academic English that they would like to learn in their discipline-specific context, including academic vocabulary, developing introductions and conclusions, structuring of essays, and writing lesson plans and rationales. They also hoped that disciplinary language courses for different year groups could be offered.

\section{Experience of online learning}

One of the key features of the discipline-specific summary writing project was that students had chances to write their summaries on a learning platform and 
obtain machine-generated feedback. This process could also be employed as a tool for supporting discipline-related language learning in the EMI context. The intended purpose of the project is to provide students an opportunity to practice summary writing skills in their own time. Students' responses show that the online summary writing platform has achieved this goal:

If more summary writing tasks or more types of writing related to reading literature were offered, I would use the platform for self-study.

(Stella)

It is good that we can get feedback on our essays without a teacher.

(Sarah)

Although the current project is only a pilot project focusing on summary writing skills, students' responses indicate that similar platforms with diverse tasks on discipline-specific summary writing could be used for their self-study.

Students commented that one particular strength of the platform was the content related feedback, as shown in the response below:

Most learning platforms can only point out grammatical mistakes. It is good that this platform offers content related scores. It is also good that we can see a sample summary so that we know what the good summary looks like.

We can compare our summaries with the good one and see if there are any differences. Just like when you take IELTS and you want to know what an essay achieving band score 9 looks like.

(Sonia)

Sally and Sonia's responses addressed a key function of the learning platform - to offer content scores and a sample summary. It seems that these offer valuable feedback for students on their discipline-specific summaries. As machine-generated content feedback was not possible using this platform, students felt unsure as to how to improve their writing in this area. Sunny pointed out that she did not receive any feedback on the logic of her writing or on her comprehension of the text. This indicates that more support from disciplinary language teachers is needed if students are to be given content related feedback.

As it is hard for the platform to generate automatic content feedback, the research team developed a self-reflection task on the platform, which asked students to self-reflect on the eight indicators of a good summary that were covered in the workshop (please refer to Appendix 4A for the self-reflection questionnaire). Students considered that the self-reflection task reminded them of the criteria of a good summary and the specific aspects they need to 
pay attention to when writing a summary, with Stella's response below as an example:

The self-reflection task provided us with a specific goal for learning. Some students often forget that they should not add their own opinions when writing a summary. When they read the self-reflection task, they are reminded how to improve.

(Stella)

Thus, it seems that the self-reflection task can be complimentary to teachers' support in some way, in particular considering that the main channel for students to obtain feedback in this project was the platform. Students recommended that the online summary writing platform could be improved in several ways, such as adding more interactive tasks on the platform, adding tutorial videos to the platform, and providing an annotated sample summary to highlight the key elements of a good summary. Such additional features would provide further chances for students to practice discipline-specific language skills at their own pace.

\section{Discussion}

The current study is a small-scale innovation project focusing specifically on summary writing as an academic writing skill and students' perceptions of EMI education in an EMI university in Hong Kong.

In response to the first research question, students' responses provide support for the previous literature that EMI education provides them better future prospects in terms of academic study, in particular in an era of internationalization (Macaro et al., 2017). At the same time, the effective implementation of EMI education is also restricted by students' and lecturers' insufficient language proficiency (Barnard, 2014). The benefits of EMI education and the challenges in implementing effective EMI education highlight the need for teaching English in a discipline-specific context, as a lack of the language proficiency hinders effective learning of subject knowledge.

Regarding the second research question, students believed that the discipline-specific summary writing workshops were more relevant and interesting than general academic English training. It was easier for students to understand the course materials and practicing writing skills in a discipline that they were familiar with. Students also articulated practical examples where they could apply the skills they obtained in the summary writing workshops (such as identifying main ideas or looking for specific information) into their own disciplinary learning. Such findings support the necessity of paying attention to students' discipline-specific language needs (Evans \& Green, 2007) and of collecting evidence on how discipline-specific language learning may facilitate students' academic study in the EMI context. 
However, some undergraduate students in the current study pointed out that the discipline-specific summary writing workshops did not fully support their discipline-specific language needs as they were not required to write articles in their academic study. Compared with undergraduate students, postgraduate students found that the workshops were more relevant and helpful. As for undergraduate students, they hope that more discipline-specific language support can be provided in learning vocabulary suitable for academic writing, developing introductions and conclusions, structuring essays, and writing lesson plans and rationales. Students' responses revealed their needs for discipline-specific language learning, and their expectation that disciplinespecific language learning should better fit their needs. Such responses indicate that a needs analysis should be conducted before the development of discipline-specific language courses in the EMI context (Huang, 2010).

As to students' perceptions of the online summary writing platform, students' responses show that it provided them with the opportunity to practice summary writing on their own initiative and to self-study thus, allowing them to self-regulate their writing development. The online learning system was considered to be helpful, as grammatical feedback and content scores were generated automatically, which facilitated self-study. Students also found the sample summary provided by the system helpful as it clarified the key aspects of a good summary. However, students hope that the online summary learning platform can become more interactive and offer training tasks for a wider variety of disciplines.

The current study also revealed the pedagogical implications of introducing EMI education into the higher education context. First, discipline-specific language courses should take into consideration students' language needs (e.g., by considering the type of writing they need in their own disciplinary courses). Second, the online learning platform needs to incorporate interactive writing tasks so that students have an opportunity to reflect on their writing and act on the feedback. Third, diverse discipline-specific learning tasks should be developed with the collaboration of language teachers and subject matter teachers, to meet the needs of students with different language proficiencies.

The limitation of the current study lies in that it is only a small-scale trial project using data collected from a single workshop as well as the online learning experience associated with that workshop. Further studies should investigate students' prolonged engagement in discipline-specific courses over a semester and on different topics.

\section{Conclusion}

The current study explores students' needs for discipline-specific language learning and investigates to what extent the summary writing workshops and an online summary training platform can meet such needs. The findings 
indicate that students have discipline-specific language needs, which need to be catered to if students are to study effectively in EMI education. The disciplinespecific learning experience can also be facilitated with online learning tools. This chapter enriches the understanding of how language teachers and universities can support students' study of subject matter courses in the EMI context by fostering their discipline-specific language proficiency. The limitation of the current study is that it only focused on the learning experience of a small number of students in a single workshop.

\section{References}

Barnard, R. (2014). English medium instruction in Asian universities: Some concerns and a suggested approach to dual-medium instruction. Indonesian Journal of Applied Linguistics, 4(1), 10-22.

Bitchener, J. (2008). Evidence in support of written corrective feedback. Journal of Second Language Writing, 17(2), 102-118. doi:10.1016/j.jslw.2007.11.004

Byun, K., Chu, H., Kim, M., Park, I., Kim, S., \& Jung, J. (2011). English-medium teaching in Korean higher education: Policy debates and reality. Higher Education, 62(4), 431-449. doi:10.1007/s10734-010-9397-4

Dearden, J. (2014). English as a medium of instruction - a growing global phenomenon. British Council. Retrieved from www.britishcouncil.es/sites/default/files/british_ council_english_as_a_medium_of_instruction.pdf

Evans, S., \& Green, C. (2007). Why EAP is necessary: A survey of Hong Kong tertiary students. Journal of English for Academic Purposes, 6(1), 3-17. doi: 10.1016/ j.jeap.2006.11.005

Hu, G., \& Lei, J. (2014). English-medium instruction in Chinese higher education: A case study. Higher Education, 67(5), 551-567. doi:10.1007/s10734-013-9661-5

Huang, L. S. (2010). Seeing eye to eye? The academic writing needs of graduate and undergraduate students from students' and instructors' perspectives. Language Teaching Research, 14(4), 517-539. doi:10.1177/1362168810375372

Hyland, K. (2002). Specificity revisited: How far should we go now? English for Specific Purposes, 21(4), 385-395. doi: 10.1016/S0889-4906(01)00028-X

Jiang, L., Zhang, L. J., \& May, S. (2019). Implementing English-medium instruction (EMI) in China: Teachers' practices and perceptions, and students' learning motivation and needs. International Journal of Bilingual Education and Bilingualism, 22(2), 107-119. doi:10.1080/13670050.2016.1231166

Joe, Y., \& Lee, H. K. (2013). Does English-medium instruction benefit students in EFL contexts? A case study of medical students in Korea. The Asia-Pacific Education Researcher, 22(2), 201-207. doi:10.1007/s40299-012-0003-7

Klein, P., Boscolo, P., Kirkpatrick, L., \& Gelati, C. (2014). Writing as a learning activity. Leiden, Netherlands: Brill. doi:10.1163/9789004265011_002

Landauer, T. K., \& Psotka, J. (2000). Simulating text understanding for educational applications with latent semantic analysis: Introduction to LSA. Interactive Learning Environments, 8(2), 73-86. doi:10.1076/1049-4820(200008)8:2;1-B;FT073

Macaro, E., Curle, S., Pun, J., An, J., \& Dearden, J. (2017). A systematic review of English medium instruction in higher education. Language Teaching, 51(1), 36-76. doi:10.1017/S0261444817000350 
Wade-Stein, D., \& Kintsch, E. (2004). Summary street: Interactive computer support for writing. Cognition and Instruction, 22(3), 333-362. doi:10.1207/s1532690xci2203_3

Walkinshaw, I., Fenton-Smith, B., \& Humphreys, P. (2017). EMI issues and challenges in Asia-Pacific higher education: An introduction. In B. Fenton-Smith, P. Humphreys, \& I. Walkinshaw (Eds.). English medium instruction in higher education in Asia-Pacific (pp. 1-18). Cham, Switzerland: Springer.

Werther, C., Denver, L., Jensen, C., \& Mees, I. M. (2014). Using English as a medium of instruction at university level in Denmark: The lecturer's perspective. Journal of Multilingual and Multicultural Development, 35(5), 443-462. doi:10.1080/ 01434632.2013.868901

Yildiz, M., Soruc, A., \& Griffiths, C. (2017). Challenges and needs of students in the EMI (English as a medium of instruction) classroom. Konin Language Studies, 5(4), 387-402.

\section{APPENDIX 4A}

\section{Students' self-reflection after writing a summary}

\begin{tabular}{|c|c|c|c|}
\hline \multicolumn{4}{|l|}{$\begin{array}{l}\text { Self-reflection after writing a summary } \\
(-)=\text { Yes. I have achieved this criterion. } \\
:=\text { = I could be doing better at this. } \\
\odot=\text { I am not doing this and I need to work on this. }\end{array}$} \\
\hline Items for reflection & (;) & $\odot$ & $\theta$ \\
\hline 1. My summary is brief and is within the word limit. & & & \\
\hline 2. I have included the main ideas. & & & \\
\hline 3. I have included the key supporting details. & & & \\
\hline 4. I did not include specific information. & & & \\
\hline 5. I did not add in my own opinions (objectivity). & & & \\
\hline $\begin{array}{l}\text { 6. My summary truly reflects the ideas in the source text } \\
\text { (no misinterpretations). }\end{array}$ & & & \\
\hline $\begin{array}{l}\text { 7. I used synthesizing and paraphrasing (no direct } \\
\text { copying). }\end{array}$ & & & \\
\hline
\end{tabular}

